\title{
Assessing the effect of nanoparticles on hyphal growth and sporulation in Ganoderma lucidum
}

\author{
Swarnjeet Singh ${ }^{1}$ and Anu Kalia ${ }^{2 *}$ \\ ${ }^{1}$ Department of Microbiology, College of Basic Sciences and Humanities, \\ ${ }^{2}$ Electron Microscopy and Nanoscience Laboratory, Department of Soil Science, \\ College of Agriculture, Punjab Agricultural University, Punjab-141004 \\ *Email: kaliaanu@pau.edu
}

Nanomaterials particularly metal/ metal oxide/ non-metal oxide nanoparticles (NPs) are increasingly being used as active ingredients of several cosmetics and other products. After use, the NPs may contaminate the soil and water resources which will be detrimental to the native soil bacteria and fungi. Therefore, the minimum inhibitory concentration of these M/ $\mathrm{MO} / \mathrm{NMO}$ NPs has to be deduced. The present investigation was carried out to evaluate the effect of three types of NPs on radial growth and ultrastructural alterations in the hyphae of saprophytic wood fungi Ganoderma lucidum.

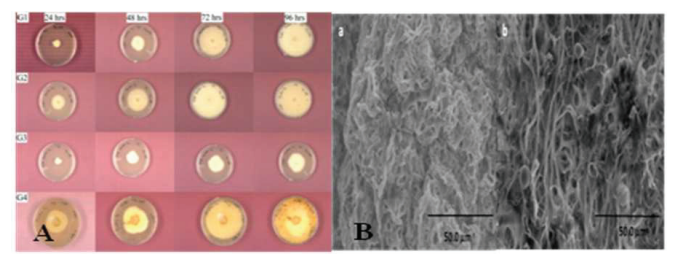

Figure 1: A) Effect of silver nanoparticles (AgNPs) (@) 100 ppm) on radial growth of fruiting and nonfruiting strains of Ganoderma lucidum at four different hours of incubation, B) Thinning of hyphae of Ganoderma lucidum strain G2 grown on MC media. (a) control, (b) 100 ppm

The four strains of Ganoderma lucidum cultivated on Mushroom Complete media $(\mathrm{MCM})+\mathrm{NPs}$ showed a numerical decrease in radial diameter of fungal colony in presence of $\mathrm{TiO}_{2}$ and $\mathrm{Ag}$ NPs at $100 \mathrm{ppm}$ (Figure 1), while the radial growth increased by supplementation of silica NPs@25 and 100 ppm concentrations. The four strains also varied significantly to NP amendments regarding the radial colony diameter (RDC) with non-fruiting strains showing higher mean RDC over fruiting strains though there is only numerical increase for 25 and $100 \mathrm{ppm}$ concentration over control. The Scanning EM (SEM) of the fungal growth showed decrease in hyphal and spore diameter in presence of NPs while the number of spores increased by NP addition in MC media.
The effect of NP supplementation was also transcended to the cellular macromolecules. The total protein content ( $\mu \mathrm{g}$ per g dry hyphal biomass) was also observed to follow similar trend as that for the radial growth. The fruiting strains G1 and G2 showed higher protein content at maximum concentration of $100 \mathrm{ppm}$ for all the three NP supplementations over nonfruiting G3 and G4 strains.

Table 1: Effect of M/ MO/NMO NPs on total protein content ( $\mu \mathrm{g}$ per $g$ dry hyphal biomass) of fruiting and non-fruiting strains of Ganoderma lucidum

\begin{tabular}{lccrrrrrrrr}
\hline Strains & \multicolumn{3}{c}{$\mathrm{TiO}_{2} \mathrm{NP}$} & \multicolumn{3}{c}{$\mathrm{SiO}_{2} \mathrm{NP}$} & \multicolumn{3}{c}{$\mathrm{Ag} \mathrm{NP}$} \\
\hline $\begin{array}{l}\mathrm{NP} \text { conc. } \\
\text { (in ppm) }\end{array}$ & 0 & 25 & 100 & 0 & 25 & 100 & 0 & 25 & 100 \\
\hline $\mathrm{G} 1$ & 1366.6 & 191.6 & 774.9 & 1366.6 & 1424.9 & 1566.6 & 1366.6 & 699.9 & 1316.6 \\
$\mathrm{G} 2$ & 1224.9 & 233.3 & 1291.6 & 1224.9 & 2183.3 & 1466.6 & 1224.9 & 1433.3 & 1058.3 \\
$\mathrm{G} 3$ & 1158.3 & 224.9 & 858.3 & 1158.3 & 916.6 & 1466.6 & 1158.3 & 591.6 & 574.9 \\
$\mathrm{G} 4$ & 908.3 & 424.9 & 508.3 & 908.3 & 1208.3 & 1524.9 & 908.3 & 674.9 & 799.9 \\
\hline $\mathrm{LSD}(0.05)$ & 154.26 & & & 188.96 & & & 158.21 & & \\
\hline
\end{tabular}

The SDS-PAGE of the crude protein extract of the Ganoderma lucidum strains showed appearance of $\sim 70$ and $18 \mathrm{kDa}$ bands in G2 strain on AgNP amendment (@100 ppm) and protein bands between 90 to $80 \mathrm{kDa}$ in G3 and G4 strains in presence of $\mathrm{SiO}_{2}$ and AgNP (@ $100 \mathrm{ppm}$ ) (Figure 2).

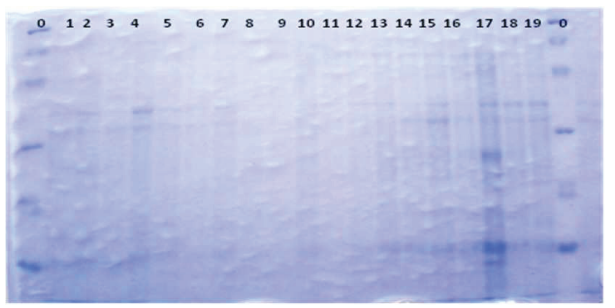

Figure 2: SDS-PAGE of the crude protein extract of the Ganoderma strains a) $1,2,3 \& 4-$ control Ganoderma strains, b) 6,7,8\&9-100 ppm $\mathrm{TiO}_{2} \mathrm{NPs}$, c) $11,12,13 \& 14-\mathrm{SiO}_{2} \quad \mathrm{NPS} \quad(100 \mathrm{ppm})$, d) $16,17,18 \& 19-$ Ag NPs (100 ppm)

\section{Reference}

1. A. Goyal, A. Kalia and H. S. Sodhi Afr. J. Micobiol. Res. 9(2015) 855-862. 